\title{
TCOM \\ Science communication for social inclusion: exploring science \& art approaches
}

\section{Ana Matias, Andreia Dias, Cláudia Gonçalves, Paulo Nuno Vicente and Ana Lúcia Mena}

\begin{abstract}
Engaging communities at risk of social exclusion poses a big challenge for science communicators. We schematize a framework for projects using science \& art to promote social inclusion, composed of 3 phases - design, plan and collaboration; implementation; and evaluation. We present a case study that aimed to engage with a community of migrant senior women, mostly illiterate. Our findings suggest high engagement was achieved by building trust, involving emotions, choosing a relatable topic and following participatory practices. Inclusive activities occurred on the short-term, but for medium-term impact, community insiders need to be regarded as a second audience.
\end{abstract}

Keywords

DOI

Introduction
Public engagement with science and technology; Social inclusion

https://doi.org/10.22323/2.20020205

Submitted: 10th July 2020

Accepted: 7th January 2021

Published: 15th March 2021

Social inclusion in science communication is a complex issue that has been addressed by different authors [e.g., Dawson and Jensen, 2011; Falk et al., 2012;

Massarani and Merzagora, 2014]. Many science communication activities intend to reach as many people as possible, and in this process of going mainstream, they may lose the under-represented groups that can only be reached with customized initiatives. Statistics of success such as number of visitors, views, 'likes', are often the only evaluation measurements of an activity/exhibition/festival/video of science communication. Yet, these metrics do not capture how diverse the publics actually are, nor they provide evidence that marginalized individuals and communities were reached.

More research on exclusion from science communication activities is needed. There is empirical research on how visitors to museums, science centres, or other informal science learning environments behave, learn, or recall their visits, however there is comparatively little research on questions of access, inclusion/exclusion, 'non-visitors' or 'new-audiences'. Research by Falk et al. [2012] that reviewed 553 articles (from 1980-2011) on 'free-choice learning' and 'informal science learning' 
found that only 27 addressed audiences considered disenfranchised in some way, suggesting that questions of exclusion from informal science education are under-researched. Dawson [2019] proposed a theory of inclusion in her book about equity, exclusion and everyday science learning, transferable to the context of science communication, in terms of (1) access and participation, and (2) recognition, representation and respect; with strong forms of inclusion practices achieved when both are high (i.e., high access and participation, and high recognition, representation, and respect). Additionally, this framework comprises three lenses for practice: infrastructure access, literacies, and community acceptance.

It is important not to forget that perhaps the most effective strategy for connecting with difficult-to-reach audiences is face-to-face conversation and other interpersonal channels [Nisbet and Scheufele, 2009]. Successful projects specifically designed for social inclusion, follow this proximity approach, such as "Native Waters: Sharing the Source" [Sachatello-Sawyer and Cohn, 2005], "Creative Canal" [Hooper Greenhill et al., 2007], "Scientific Racism" [Foggett, 2008], “Urban Garden" [Fusco and Barton, 2001], "Knowledge Rooms" [Streicher, Unterleitner and Schulze, 2014], "Parque Explora" [Aguirre, 2014] and "Questioning Workshops" [Perié, Riboli-Sasco and Ribrault, 2014].

There is a broad consensus among governments, industry, and the science communication community that more needs to be done to increase and widen participation in science [Archer et al., 2015]. Yet, how can we reach distant publics with no interest in science? How can we make socially inclusive science communication programmes? How to tailor science communication activities in ways that are engaging to those audiences?

Arts can deeply engage people by focusing on the affective domain of learning rather than on the cognitive domain [Friedman, 2013] and by bringing science to the public in ways that are engaging, instructive, artistic and content-driven [Schwartz, 2014]. Strategies fusing arts and science had renewed interest over the last decades [Heras and Tábara, 2014]. Following this, STEAM (Science, Technology, Engineering, Mathematics + Arts and Humanities) integrations and cross-pollinations are becoming more relevant than ever [de la Garza and Travis, 2019]. Examples of Science \& Art projects for science communication are art installations inspired in neuroscience laboratories [Lopes, 2015], theatre as a way of communicating coastal risk [Brown et al., 2017], or creative dance as a way of engaging with coastal geoscience [Matias, Carrasco et al., 2020].

We proposed to investigate if a science communication programme based on science and art approaches could promote the engagement in science and culture of a disenfranchised community. In this article, we present a programme framework that was designed as a participatory project, giving opportunities for the community to explore and represent perspectives in their own terms. It is an exploratory programme where the emphasis is not just on outcomes, but also on the process itself. We explore ways to bring science closer to a community with limited education and resources, using unconventional techniques and artistic tools. The project was evaluated using a number of indicators, through which it was possible to conclude that engagement with the programme was high. Our work suggests that science \& art tailored communication programmes are adequate and powerful tools to engage with distant publics. 
A programme framework for socially inclusive science communication
We schematized a programme framework for science communicators that intend (and have the resources) to engage with communities that face diverse types of barriers to inclusion, such as age, gender, ethnicity, social status, physical impairment, which can be regarded as 'new-audiences' or 'non-visitors'.

Our methodology assumes the main programme objective is not to increase the knowledge of a target audience on a scientific subject, aligned with top-down visions of science communication (as the science literacy paradigm described, e.g., by Bauer, Allum and Miller [2007]). Rather we adopt a multiple approach where other achievements are equally valued. A very important step is the setting of objectives, which in turn influence evaluation and thus the success of the programme. We propose eight objectives: 1) to increase awareness of science; 2) to increase knowledge of scientific topics; 3 ) to stimulate creativity, curiosity, abstraction and self-expression; 4) to accomplish engagement with the project; 5) to promote engagement with science; 6) to encourage the community's willingness to participate in new cultural experiences; 7) to provide cultural experiences; and 8) to foster closer relationships between communities distant to science and cultural experiences.

The programme entails the following phases [adapted from Varner, 2014]: Phase 1 — Design, plan and collaboration; Phase 2 - Implementation; and Phase 3 Evaluation (Figure 1).

Since our programme follows science \& art approaches to promote science communication with disenfranchised communities, we propose that Phase 1 starts by the definition of partners, and establishment of collaborations. Programmes involving significant interdisciplinary and multiple partners bring into the arena people and organizations with different backgrounds, practices, languages, and purposes that may be misaligned. To address these issues, it is important to have individuals who mediate between the different social groups - the boundary spanners (BS), who effectively inhabit multiple social entities [Kirby, 2008]. Many science communicators act in the role of BS within their groups or organizations to bridge boundaries.

The definition of the specific goals, besides the ones mentioned above, can include community building, entertainment, health improvement, environmental behaviour change, art education, fundraising, and institutional marketing.

After the specific objectives are set, the session's layout and structure are defined, as well as an evaluation plan, identifying qualitative and quantitative indicators according to the specific characteristics of the project and audience. Some need to be gathered before or during the early stages of the programme implementation. (More about the evaluation phase below.)

Phase 2 consists in sessions planning and their execution, data collection for evaluation, and informal formative evaluation (Figure 1). The sessions progress should follow a narrative arc, i.e., the way sessions evolve should tell a story and increase in intensity and complexity. The programme implementation specific attributes are dependent upon, amongst others: ambition of goals; interest and level of engagement of the several partners; complexity of the topic and degree of depth into it; human resources availability and profile; space availability, quality 


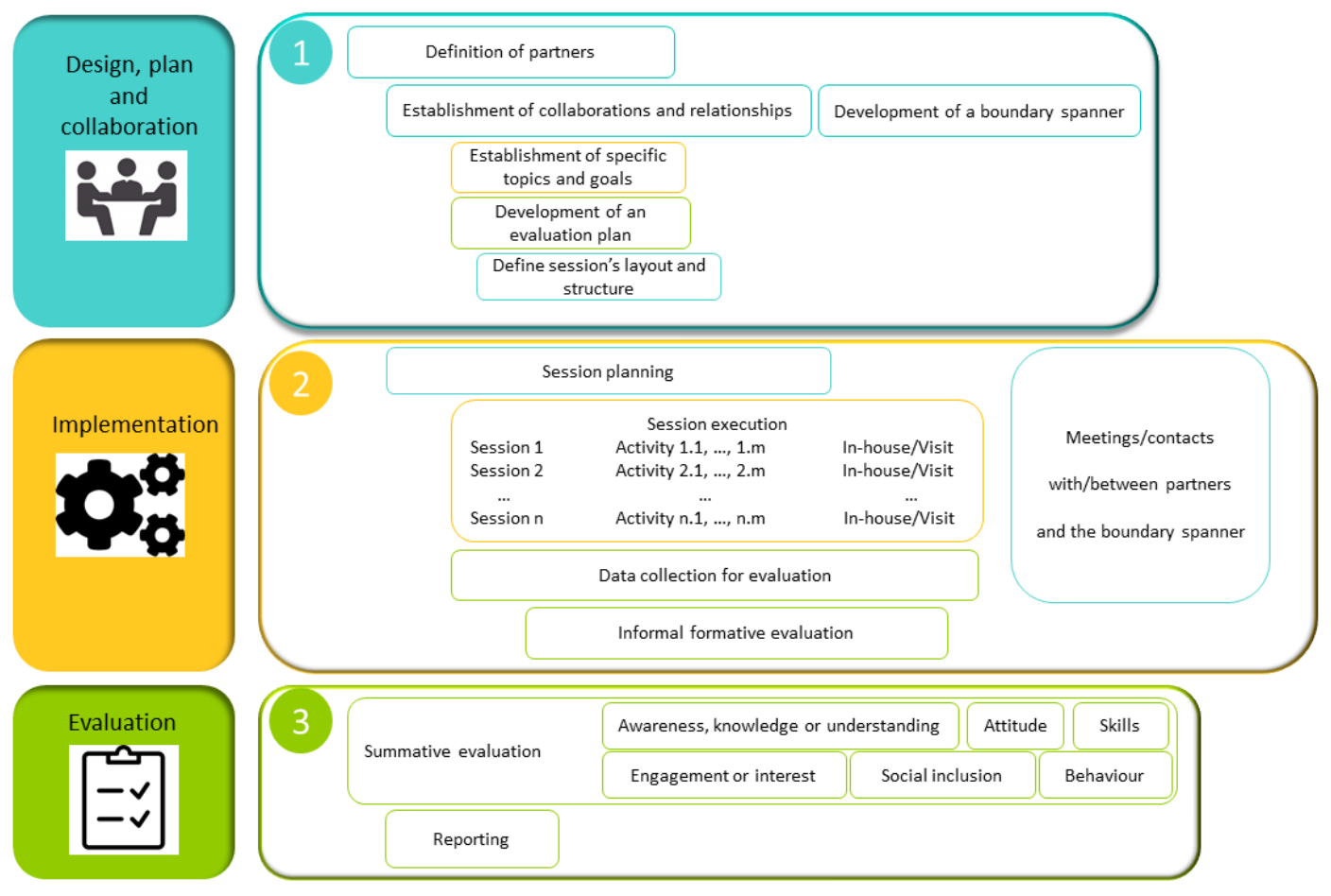

Figure 1. Proposed programme framework for science communication projects using Science \& Art to promote social inclusion. Programme phase limits are not rigid. Elements from several phases should take place simultaneously, such as session planning (related to planning - Phase 1) or data collection for evaluation (related to evaluation - Phase 3) occurring during the implementation (Phase 2).

and features; equipment and materials availability and quality; transportation means; type of artistic techniques to use; and financial support. Sessions that rely solely on lectures should be avoided.

To ensure its collaborative nature, sessions planning and executions need to be at the same time loose enough to accommodate the adjustments proposed by the several partners, but straightforward enough to make good use of available resources, and keep the story on track.

The last phase (Phase 3) is the project evaluation. The evaluation of science communication programmes is neither an easy task nor a consensual one. Providing the causal effect of one particular intervention (over and above other experiences) and thereafter claiming impact is extremely difficult [King et al., 2015]. According to Jensen [2014] there is no achievable science communication goal that is impervious to robust measurements using social scientific tools. Several evaluation methods can be adopted (e.g., Moss, Jensen and Gusset [2014] and Kennedy, Jensen and Verbeke [2018]). Given the specific nature of socially inclusive science communication projects, we based our evaluation method on the Framework for Evaluating Impacts of Informal Science Education Projects [Allen et al., 2008].

The evaluation starts by the identification, adapted case-by-case, of the impacts envisioned for the project, which in turn are related to the project objectives. We propose the following four impact categories: 1) Awareness and knowledge; 
2) Engagement; 3) Attitude; 4) Social inclusion (see on Table 1 how these categories relate with objectives defined above), for which evidences need to be collected using several indicators, i.e., assessment techniques. Allen et al. [2008] methodology also include behaviour and skills as impact categories (also in summative evaluation in Figure 1), however, we did not include them for this work because the duration and nature of this project is not adequate for behavioural changes nor skills acquisition.

When dealing with social inclusion, evaluation methods should consider the public's characteristics. Therefore, it may be necessary to use qualitative methods to include the opinion and perception of, for example, illiterate participants and foreign language participants, persons with visual impairment, motor impairment, reading or writing difficulties. In section 3.3 we provide details on indicators to evaluate projects dealing with illiterate audiences.

\section{Programme "Embodying Memories" - a case study}

\subsection{Phase 1 - Design, plan and collaboration}

In this case study, the target audience was chosen after a series of contacts and meetings with the social workers of Oeiras Municipality. The audience was an underprivileged community composed of 14 women, 13 of which migrants from the Republic of Cabo Verde, living in Oeiras municipality (Portugal). Their age ranged from 64 to 84 years, had low literacy levels (five participants completed the fourth grade, six never attended school) and low socioeconomic status. All women were retired from jobs that require almost no scholar qualifications, such as factory manual workers, housekeepers, and fish sellers. They were under a rehousing programme from slum dwellers and were assembled as a group about a year before this project.

The project brought together two science communicators, a Ph.D. student in neuroscience from Gulbenkian Institute of Science (IGC, in Portuguese), a researcher in science \& art, an art education professional from Calouste Gulbenkian Museum with experience in visual and performative arts, and a social worker from the Oeiras municipality. One of the science communicators worked as a boundary spanner, inhabiting the laboratory sphere, the museum sphere, and the community world. This was achieved by meetings and activities with the partners/community during Phase 1.

The choice of topic in neurosciences was made with our audience, based on their interests, during informal meetings that took place during Phase 1. The topic 'Memory' acknowledges, on the one hand, the community's significant attachment to old memories from experiences lived in Africa, and on the other hand, some concerns expressed by the community on short-span memory deterioration.

\subsection{Phase 2 - Implementation}

The project implementation consisted in eight sessions that occurred during 2 months of 2018, with a duration of 90-120 minutes each. Sessions included diverse themes and formats, from more explanatory to more interactive, from in-door sessions to visits to the museum and laboratories. 
Most sessions occurred at the Local Support Centre for the Integration of Migrants, in Outurela - Carnaxide, where they regularly meet. This local was perceived by the participants as a familiar place. One session occurred at the Calouste Gulbenkian Museum, in Lisbon, and another at the Gulbenkian Institute of Science, a research centre in Oeiras. These visits were planned to promote a closer contact between the project's participants with art and science "houses".

In-door sessions followed the generic scheme: 1) initial group reception and room arrangement, 2) summary of previous activities, 3) conversation segment about the session theme, 4) practical activities using artistic techniques and narratives in relation to the theme; and 5) wrap-up of the session using keywords. These keywords were collected and revisited in each session. A comprehensive description of activities can be found as Supplementary Material.

Because of the target audience's specific characteristics, the entire project was designed to allow illiterate people participation. This implied that no game or activity could require reading, and the community participants could not take notes. Moreover, technological devices (computers, tablets, smart phones) were avoided as much as possible since all depend on some degree of literacy. All scientific or artistic images were on paper or visualized on a computer screen.

During Sessions 1 and 2, participants talked about memories related to personal objects of their choice (Figure 2a). The neuroscientist presented the organ where all those memories are stored - the brain (Figure $2 b$, session 1 ), the brain functions (Session 2), the brain development (Session 3), the concept of cells in the human body, and in particular neurons, and how neurons connect in networks (Session 4). Stories or cases studies (e.g. Phineas Gage accident survival on Session 2) were used, and many times the neuroscientist related science concepts with the memories shared by participants.

Session 5 was a visit to the museum in Lisbon, that houses the founder's private collection, alongside a collection of modern and contemporary art (Figure 3). The visit was organized and adapted from an activity of the museum educational service.

All keywords collected in previous sessions were used in the sixth session, in an activity (Figure $2 \mathrm{~g}$ ) that resulted in a poem created by the participants:
From Cape Verde dressed in courage,
We drank hope from the babies at home,
I have beautiful memories from my neighbourhood,
I'm grateful for the love inside the museum, and
$I^{\prime} m$ happy that my brain is connected to the Migrant Support Centre. ${ }^{1}$

Session 7 took place at the research centre. This visit was planned to show the spaces where the neuroscientist works (Figure 4). IGC researchers and technicians were mobilized to explain their scientific instruments, laboratory techniques, research objects, and scientific models. Session 8 focused on collecting data for project's evaluation (Figure 2h, described in section 3.3).

\footnotetext{
${ }^{1}$ Free translation from Portuguese.
} 

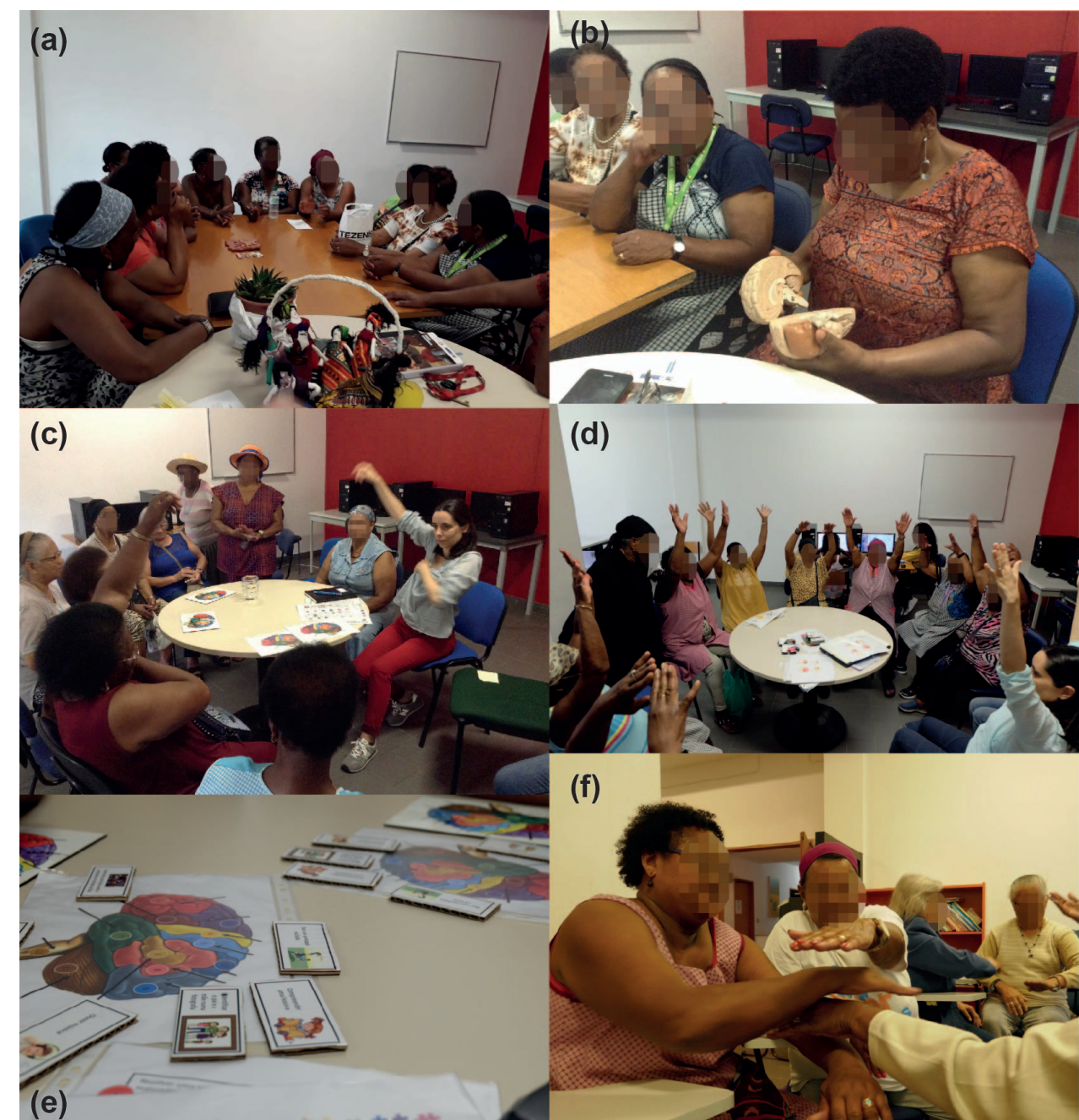

(d)

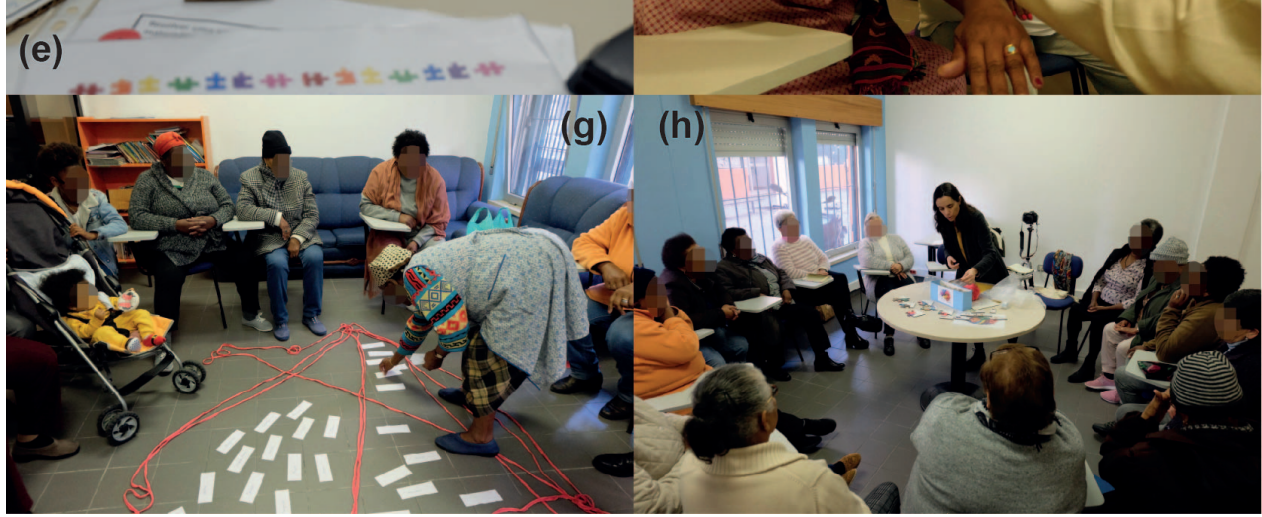

Figure 2. Photographs of in-house sessions. (a) Session 1 with memory objects; (b) Session 1 with the brain model; (c) Session 2, mimic of dressing; (d) Session 3, movement representing brain growth; (e) Session 3, game of brain regions and functions; (f) Session 4, arm dance coordination activity; (g) Session 6, collection of words during the poetry activity; (h) Session 8 , project narrative.

Then, the project's public presentation was prepared by the community, BS, and social worker. It took place at a concert hall nearby and consisted of a sequence of individual statements about the project, created and recited by participants and the BS, while a network of fabric yarn was created on stage. The placement on stage, wardrobe, sequence and props were discussed, prepared and rehearsed by the community and the BS. A small exhibition of memory objects was put on display. 


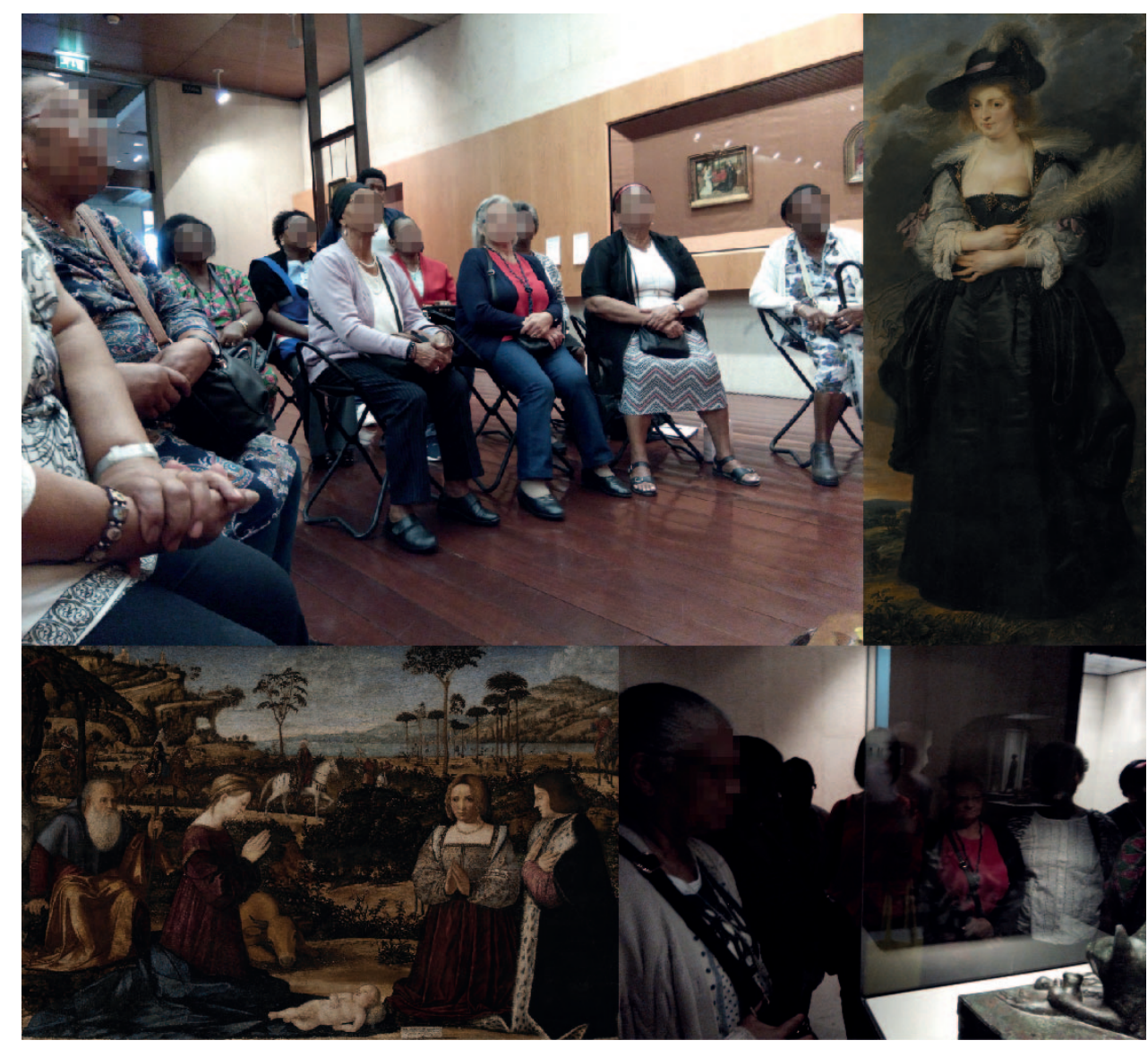

Figure 3. Photographs at the museum, and images from the two favourite paintings in the museum collection. Top right: portrait of Helene Fourment, by Peter Paul Rubens, ca. 163032; bottom left: Holy Family and Donors by Vittore Carpaccio, 1505; (c) Calouste Gulbenkian Foundation.

\subsection{Phase 3 - Evaluation}

For this project evaluation, no questionnaires or written information could be used. Six assessment techniques were applied to collect evidence: focus groups, attendance record sheet, open-ended questions and ethnography (observational field notes, self-narrative(s) at a session, and at the public presentation). To address the community's perception and involvement with science, two semi-structured focus groups were conducted before and after Phase 2 sessions. Field notes were collected throughout the project and used to assess impact on several categories. Participant's attendance in the sessions was recorded, and served as a measure for engagement. After the end of all sessions, participants were asked to evaluate the project by stating what they liked more, what liked less, and what was more relevant, hereafter called open-ended questions. Participants were asked to describe the project contents in their own words, creating a project narrative. The focus groups, open-ended questions and project narrative were audio recorded and transcribed.

Data obtained by the six assessment techniques (Table 1) was analysed, and each objective's impact qualitatively evaluated in the following ranks: none, some, moderate, high and very high. Complete description of evaluation methods available as Supplementary Material. 


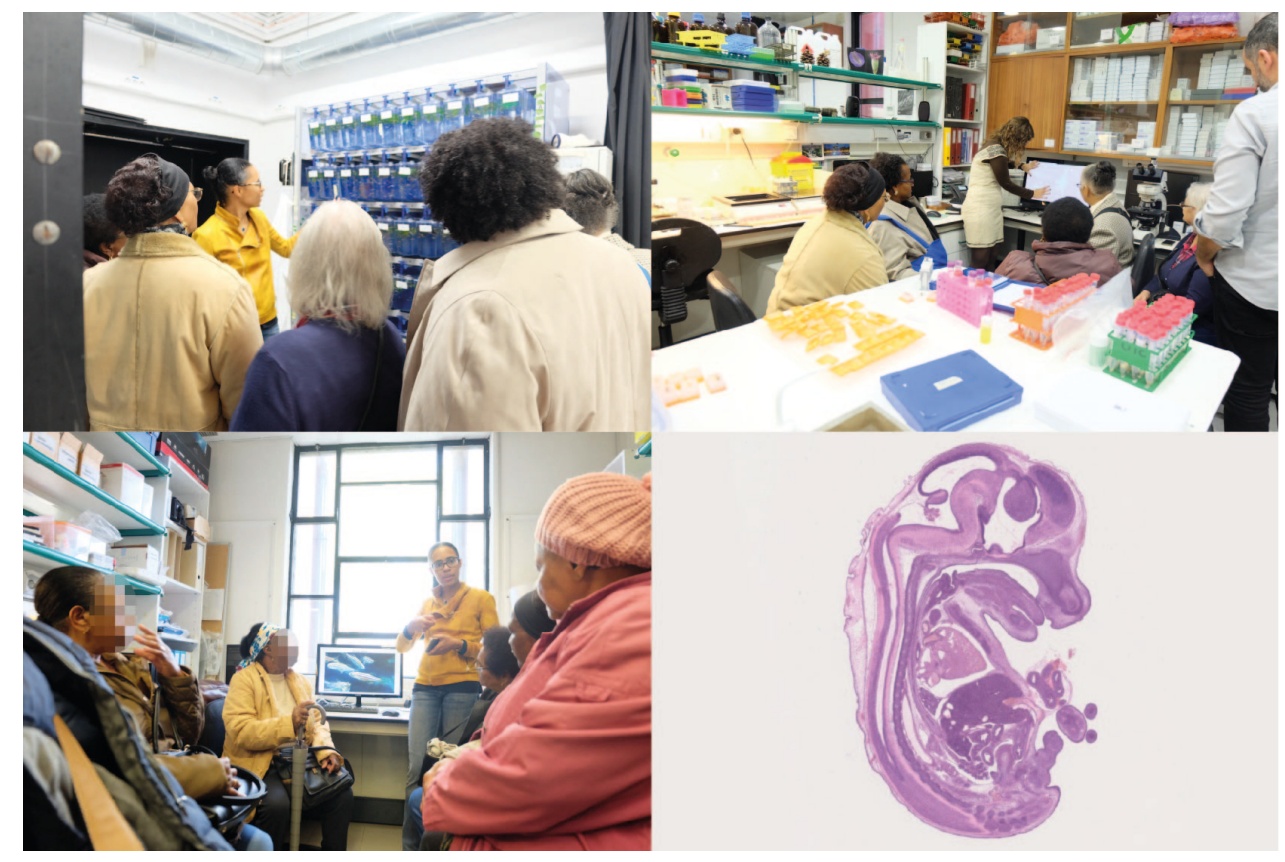

Figure 4. Photographs at IGC, and an image from an embryo section from the Histopathology Unit. (C) Gulbenkian Institute of Science.

Table 1. Proposed objectives for the science communication programme framework, and expected impact categories.

\begin{tabular}{|c|c|c|}
\hline Objectives & $\begin{array}{c}\text { Impact } \\
\text { categories }\end{array}$ & Indicator \\
\hline $\begin{array}{l}\text { 1) to increase awareness of science, } \\
\text { 2) to increase knowledge of scientific topics, } \\
\text { 3) to stimulate creativity, curiosity, } \\
\text { abstraction and self-expression. }\end{array}$ & $\begin{array}{l}\text { Awareness } \\
\text { and } \\
\text { Knowledge }\end{array}$ & $\begin{array}{c}\text { Focus groups } \\
\text { Observational field notes } \\
\text { Self-narrative (sessions) } \\
\text { Self-narrative } \\
\text { (public-presentation) }\end{array}$ \\
\hline $\begin{array}{l}\text { 4) to accomplish engagement with the } \\
\text { project } \\
\text { 5) to promote engagement with science }\end{array}$ & Enga & $\begin{array}{c}\text { Attendance record } \\
\text { Observational field notes } \\
\text { Self-narrative (sessions) }\end{array}$ \\
\hline $\begin{array}{l}\text { 6) to encourage the community's } \\
\text { willingness to participate in new cultural } \\
\text { experiences }\end{array}$ & Attitude & $\begin{array}{c}\text { Observational field notes } \\
\text { Self-narrative } \\
\text { (public-presentation) }\end{array}$ \\
\hline $\begin{array}{l}\text { 7) to provide cultural experiences, } \\
\text { 8) to foster closer relationships between } \\
\text { communities distant to science and cultural } \\
\text { experiences }\end{array}$ & $\begin{array}{l}\text { Social } \\
\text { Inclusion }\end{array}$ & $\begin{array}{c}\text { Attendance record } \\
\text { Open-ended questions } \\
\text { Observational field notes } \\
\text { Self-narrative (sessions) } \\
\text { Self-narrative } \\
\text { (public-presentation) }\end{array}$ \\
\hline
\end{tabular}

On the Awareness and Knowledge Category (Table 1), data from pre-sessions focus group revealed science unawareness, misconception (for instance, science was confused with schooling) or crude notion (e.g., "science is related to astronauts"), and very limited scientific background. Post-sessions focus groups showed some evolution of scientific concepts; and project narrative evidenced some gains on understanding of the human brain (e.g., "babies start to hear and communicate 
with their mothers before being born, after a certain point"). Our results also reveal that the participants became aware of scientific instrumentation, objects of science, laboratories and scientists (during project narrative words such as "microscope", "sample", "zebrafish", "aquarium", were used). Throughout the sessions, a lack of creativity, curiosity and abstraction was evident, and only some improvement was noticed. Participants gain some confidence and willingness to self-express about subjects and events that pushed them outside of their everyday lives. Overall, impact on Awareness and Knowledge category was rated "Some".

In relation to Engagement (Table 1), no participant dropped out of the project. The active participation during sessions proved the community was not just there; they were engaged. There were, nevertheless, differences within the community engagement that seem to be related to participants' personalities. These differences at times biased the analysis; one participant in particular, tended to speak more and her opinion may have shadowed others. In relation to engagement with science, the evaluation indicators showed the possibility that, under particular conditions, the community may become a new public of science. Participants were able to relate the scientific content with personal issues; but this was underlying from the outset of the project since the topic was chosen after hearing the community. Overall, impact on Engagement was rated "High".

Regarding the impact category Attitude, by the end of the project it was observed a "High" willingness to participate in new cultural experiences, as it was expressed by several participants that would like to revisit the science institute and the museum.

The final category assessed was Social Inclusion. The mutual reliance between the BS/science communicator and the community, gained along the project development, gave the community trust to participate on the museum and IGC's laboratories visits. The community participated and enjoyed the cultural experiences, tailored to their interests and needs. All participants entered a museum and a scientific institution for the first time. The community felt that they learned new things, enjoyed the visits and were able to self-express about scientific objects or instrumentation. Furthermore, they expressed a wish to undertake more cultural experiences. Overall, impact on Social Inclusion was rated "Moderate to High".

Discussion: "Embodying Memories" as a case study on how to reach and engage disenfranchised communities in science
Science communication projects may encounter many barriers identified in previous studies of accessibility and social exclusion from science (e.g., Dawson [2018]), such as: age, gender, schooling, ethnicity, social status, income, geographic location, and job profile. The project "Embodying memories" was undertaken with a community apart from science due to a greater or lesser degree of all the above-mentioned exclusion factors. A project with such features can provide insights into positive and negative aspects about how to reach distant publics, and which strategies (do not) work.

The community neighbourhood has access to radio broadcasting, national and cable television, internet, newspapers, and is at a 15-min drive distance to, for example, a concert hall, public garden, museum, library, and a 30-min drive distance to the capital city, with a rich cultural offer. Yet, the community does not 
enjoy or exercise the right to these events and resources. This fact informed us, right from the start, that ongoing national and local strategies were excluding this community; that science centre/museum prior offer was not reaching this community; and thus, to engage with them a tailored programme needed to be develop.

According to our analysis, the participants' engagement with this project was high, and we believe there are several reasons contributing to this achievement. We consider the establishment of trust between all participants essential for effective communication (as discussed by Nisbet and Scheufele [2009]) and promotion of social inclusion in science. In the case study, at first, all actors had reservations and did not know what to expect. Ever since the development of the BS during Phase 1, reciprocal trust increased with mutual acquaintance and shared occasions. This is one of the reasons why the proposed framework gives so much emphasis to Phase 1.

Still in Phase 1, the topic choice was crucial for science engagement to take place. "Memories" was decided after hearing the audience needs and concerns. It is a topic that appreciates diversity, can elicit emotions, allows for clear transference of science knowledge to everyday life, it is bursting with suggestive processes and images suitable for artistic approaches, and for which all partners have different perspectives.

Likewise, an attribute of Phase 2 which we believe contributed for high engagement was the adoption of a participatory model, giving opportunities for the community to explore and represent perspectives in their own terms. The first session of Phase 2 was driven by participant's description of objects and memories from Africa; and activities thereafter, were done in a collective way, as a dialogue with the community, stimulating curiosity and self-expression. We believe as Metcalfe, Riedlinger and Pisarski [2008] stated, that these participatory models are able to situate science within the social context, and therefore enhance engagement.

Also, in Phase 2 we adopted a science \& art approach, which may have contributed to high engagement. It is known that artistic techniques evoke emotions (e.g., [Pinto and Riesch, 2017; Stiller-Reeve and Naznin, 2018]), activate processes of participation and dialogue (e.g., [Curtis, Reid and Ballard, 2012]), and play the role of mediator between science and society (e.g., [von Roten and Moeschler, 2007; Opermanis, Kalnins and Aunins, 2015]). During the visit to the museum, one of the participants stated "The museum is full of love", while another stated "We found many beautiful things; we don't have that around us". These positive emotions were important, not only during the visit itself, but, more importantly, for personal bonding.

Another achievement observed during the course of Phase 2, unforeseen in Phase 1 setting of the objectives and evaluation, was the establishment of a focused, fluid, and suitable session environment. When sessions started, there were constant interruptions for participants to solve personal issues; the community's concentration span was limited, grandsons at their care distracted their attention, and an overall dispersion was noticed. Through time, almost all of this disappeared, with the last session taking place in a focused way. This achievement is important on its own in a practicing culture of science learning, as pointed out by Fusco [2001]. 
On the negative side, according to our analysis, the category with lower score was the knowledge of scientific topics. The community had problems with memory and mental plasticity, related to aging, poor stimulation or disease. Some participants tended to forget what occurred during previous sessions, namely a participant who developed a neurological condition that compromises the memory; and another that showed clear evidences of engagement with the project but failed to express her thoughts, and stated:

My head is not the same. My memory is failing me. ${ }^{2}$

The scarcity of offer to this community that promote intellectual stimulation and enrichment, generated a feeling of gratitude towards the science communicator and the BS. Whereas most of our audience could not read or write, unable to take notes and rely only on their memories, having (even if just) some increase in scientific knowledge should be regarded as positive. We believe that Phase 2 was short to address this objective. The question remains, how long should the programme duration be extended to provide enough knowledge impact? Informal formative evaluation (Phase 2) using the impact assessment described in Phase 3, needs to be carried out to monitor this impact.

Also, on the down side, we have evidences that the medium-term repercussions of the project are questionable. Anecdotal evidence from this project shows that 2-months duration is insufficient for so marginalized audiences, such as the ones we have encountered in this research. Latter contacts with the community showed that two years after the project ended, there was no continuity of activities or visits related to science or art by the community.

On a short-term perspective, the opportunity given to participants to engage with science \& art, to visit the museum and laboratories, to meet scientists and science instruments, was a social inclusion achievement on its own. One participant stated:

"This was a once-in-a-life-time experience."

Another participant actually used the word "courage" to express what it took her to participate.

Community members may be more receptive, but limitations in transportation, access to culture programmes, physical limitations, financial limitations, as well as decades of exclusion and isolation may delay or inhibit such initiatives. Removing barriers does not mean that the community will better engage in science and culture events, as stated by Dawson [2014]. In the immediacy of the project, further participation in cultural activities, even if sporadic, depends on the social worker. The social worker had a very important role in the project execution. The community contacts were limited to face-to-face or telephone, as no texting or email was possible. Nevertheless, the involvement of the social worker in the project could have been more significant, had her role in the project been better discussed at the beginning. She is aware of the group limitations, thus protects them from experiences that she believes will make them feel diminished.

\footnotetext{
${ }^{2}$ Free translation of Portuguese language.
} 
Therefore, based on this project we believe that there were actually two audiences for this project: the community and the social workers. If the project was successful in the short-term engagement with the community, it failed on the engagement with the social workers. Our lesson from here is that specific actions should have targeted the social workers (the 'insiders') that would in turn be the drivers of further cultural inclusion.

\section{Conclusions}

The project "Embodying memories" was an innovative exploratory project by the way it combined science, art and science communication to engage with a community excluded from most cultural events. The study demonstrates how art can contribute to the engagement with the project, how openness and trust can contribute to communication effectiveness, and how science can relate to everyday life.

Based on our experimental research we systematized a programme framework, helpful for practitioners that can create the means for longer duration projects, and for which we suggest as minimum of: (1) two-person team for session's execution; (2) one cultural visit outside the community space; (3) one session devoted to stimulate creativity, abstraction, curiosity; (4) interaction with several art forms; (5) one direct contact with a science professional; (6) one activity demonstrative of the relation between the scientific topic and an issue of everyday life; and (7) availability for more than two months project implementation.

Our outcomes suggest that tailored science communication programmes, fully adjusted to the characteristics and needs of the target audience, can reach and engage distant publics at the short-term. Nonetheless, the medium-term repercussions of the project are questionable as the community was not empowered to take further actions. Moreover, the social workers (insiders) were not considered a target, thus their increased awareness and support to carry on cultural inclusion was not nurtured. This seams an important issue to consider during Phase 1 of future projects.

Data availability and supplementary material

Acknowledgments
The dataset analysed within this paper and further details on the project execution are freely available via Figshare: https:/ / doi.org/10.6084/m9.figshare.12577940.v1 [Matias, Dias et al., 2021].

We thank Oeiras City Hall and the social worker Maria da Assunção Tavares for their valuable support to the project. We acknowledge Champalimaud Foundation Research Centre for the human brain model. A. Matias was supported by Investigator Programme, IF/00354/2012 and institutional contract under the D.L. n. 57/2016 changed by Law n. 57/2017 all financed by Fundação para a Ciência e a Tecnologia (FCT), Portugal. A.L. Mena was supported by a fellowship under the research and development unit UID 04555, financed by FCT. 
Aguirre, C. (2014). 'Science Centers. Which role can they play to participate in a city social reconstruction?' JCOM 13 (02), C04. https://doi.org/10.22323/2.13020304.

Allen, S., Campbell, P. B., Dierking, L. D., Flagg, B. N., Friedman, A. J., Garibay, C., Korn, R., Silverstein, G. and Ucko, D. A. (2008). Framework for evaluating impacts of informal science education projects. Report from a National Science Foundation Workshop. Ed. by A. J. Friedman. The Division of Research on Learning in Formal and Informal Settings (DRL). URL: https : / www . informals cience.org/sites/default/files/Eval_Framework.pdf.

Archer, L., Dawson, E., DeWitt, J., Seakins, A. and Wong, B. (2015). “"Science capital": a conceptual, methodological, and empirical argument for extending bourdieusian notions of capital beyond the arts'. Journal of Research in Science Teaching 52 (7), pp. 922-948. https://doi .org/10.1002/tea.21227.

Bauer, M. W., Allum, N. and Miller, S. (2007). 'What can we learn from 25 years of PUS survey research? Liberating and expanding the agenda'. Public Understanding of Science 16 (1), pp. 79-95. https://doi.org/10.1177/0963662506071287.

Brown, K., Eernstman, N., Huke, A. R. and Reding, N. (2017). 'The drama of resilience: learning, doing, and sharing for sustainability'. Ecology and Society 22 (2), 8. https://doi .org/10.5751/ES-09145-220208.

Curtis, D. J., Reid, N. and Ballard, G. (2012). 'Communicating ecology through art: what scientists think'. Ecology and Society 17 (2), 3. https://doi.org/10.5751/ES-04670-170203.

Dawson, E. (2014). 'Reframing social exclusion from science communication: moving away from 'barriers' towards a more complex perspective'. JCOM 13 (02), C02. https://doi .org/10.22323/2.13020302.

- (2018). 'Reimagining publics and (non) participation: exploring exclusion from science communication through the experiences of low-income, minority ethnic groups'. Public Understanding of Science 27 (7), pp. 772-786. https://doi.org/10.1177/0963662517750072.

- (2019). Equity, exclusion and everyday science learning. The experiences of minoritised groups. London, U.K.: Routledge.

Dawson, E. and Jensen, E. (2011). 'Towards a contextual turn in visitor studies: evaluating visitor segmentation and identity-related motivations'. Visitor Studies 14 (2), pp. 127-140. https://doi .org/10.1080/10645578.2011.608001.

de la Garza, A. and Travis, C. (2019). 'Introduction'. In: The STEAM Revolution. Ed. by A. de la Garza and C. Travis. Cham, Switzerland: Springer, pp. 1-10. https://doi.org/10.1007/978-3-319-89818-6_1.

Falk, J., Osborne, J., Dierking, L., Dawson, E., Wenger, M. and Wong, B. (2012). Analysing the U.K. science education community: the contribution of informal providers. London, U.K.: Wellcome Trust.

URL: https://wellcomelibrary . org/item/b21248023\#? c=0\&m=0\&s=0\&cv=0.

Foggett, M. (2008). Community consultation at the Dana Centre: an audience-led project between London's African-Caribbean community and the Science Museum. London, U.K.: Audience Research \& Advocacy Group. Learning Unit. The Science Museum.

Friedman, A. J. (2013). 'Reflections on communicating science through art'. Curator: The Museum Journal 56 (1), pp. 3-9. https://doi.org/10.1111/cura.12001.

Fusco, D. (2001). 'Creating relevant science through urban planning and gardening'. Journal of Research in Science Teaching 38 (8), pp. 860-877. https://doi.org/10.1002/tea.1036. 
Fusco, D. and Barton, A. C. (2001). 'Representing student achievements in science'. Journal of Research in Science Teaching 38 (3), pp. 337-354. https://doi .org/10.1 002/1098-2736(200103) 38:3<337: :AID-TEA1009>3.0.CO;2-0.

Heras, M. and Tábara, J. D. (2014). 'Let's play transformations! Performative methods for sustainability'. Sustainability Science 9 (3), pp. 379-398. https://doi.org/10.1007/s11625-014-0245-9.

Hooper Greenhill, E., Dodd, J., Creaser, C., Sandell, R., Jones, C. and Woodham, A. (2007). Inspiration, identity, learning: the value of museums. Leicester, U.K.: Research Centre for Museums and Galleries (RCMG). University of Leicester. URL: https://www2.le.ac.uk/departments/museumstudies/rcmg/projects/i nspiration-identity-learning-2/DCMS2.pdf.

Jensen, E. (2014). 'The problems with science communication evaluation'. JCOM 13 (01), C04. https://doi.org/10.22323/2.13010304.

Kennedy, E. B., Jensen, E. A. and Verbeke, M. (2018). 'Preaching to the scientifically converted: evaluating inclusivity in science festival audiences'. International Journal of Science Education, Part B 8 (1), pp. 14-21. https://doi.org/10.1080/21548455.2017.1371356.

King, H., Steiner, K., Hobson, M., Robinson, A. and Clipson, H. (2015). 'Highlighting the value of evidence-based evaluation: pushing back on demands for 'impact'. JCOM 14 (02), A02. https://doi.org/10.22323/2.14020202.

Kirby, D. A. (2008). 'Hollywood knowledge: communication between scientific and entertainment cultures'. In: Communicating science in social contexts. New models, new practices. Ed. by D. Cheng, M. Claessens, T. Gascoigne, J. Metcalfe, B. Schiele and S. Shi. Dordrecht, Netherlands: Springer, pp. 165-180. https://doi.org/10.1007/978-1-4020-8598-7_10.

Lopes, M. M. (2015). 'Intertwined artistic practices: critical remarks on collaboration across fields of knowledge'. MIDAS: Museus e Estudos Interdisciplinares 5. https://doi.org/10.4000/midas.856.

Massarani, L. and Merzagora, M. (2014). 'Socially inclusive science communication'. JCOM 13 (02), C01. https://doi .org/10.22323/2.13020301.

Matias, A., Carrasco, A. R., Ramos, A. A. and Borges, R. (2020). 'Engaging children in geosciences through storytelling and creative dance'. Geoscience Communication 3 (2), pp. 167-177. https://doi .org/10.5194/gc-3-167-2020.

Matias, A., Dias, A., Gonçalves, C., Vicente, P. N. and Mena, A. L. (2021). 'Data from 'Science communication for social inclusion: exploring Science \& Art approaches". Figshare. https://doi.org/10.6084/m9.figshare.12577940.v1.

Metcalfe, J., Riedlinger, M. and Pisarski, A. (2008). 'Situating science in the social context by cross-sectoral collaboration'. In: Communicating science in social contexts. New models, new practices. Ed. by D. Cheng, M. Claessens, T. Gascoigne, J. Metcalfe, B. Schiele and S. Shi. Dordrecht, Netherlands: Springer, pp. 181-197. https://doi .org/10.1007/978-1-4020-8598-7_11.

Moss, A., Jensen, E. and Gusset, M. (2014). A global evaluation of biodiversity literacy in zoo and aquarium visitors. Gland, Switzerland: World Association of Zoos and Aquariums (WAZA).

Nisbet, M. C. and Scheufele, D. A. (2009). 'What's next for science communication? Promising directions and lingering distractions'. American Journal of Botany 96 (10), pp. 1767-1778. https://doi.org/10.3732/ajb.0900041.

Opermanis, O., Kalnins, S. N. and Aunins, A. (2015). 'Merging science and arts to communicate nature conservation'. Journal for Nature Conservation 28, pp. 67-77. https://doi.org/10.1016/j.jnc.2015.09.005. 
Perié, L., Riboli-Sasco, L. and Ribrault, C. (2014). 'Straight into conflict zones, scientific research empowers the minds'. JCOM 13 (02), C05. https://doi.org/10.22323/2.13020305.

Pinto, B. and Riesch, H. (2017). 'Are audiences receptive to humour in popular science articles? An exploratory study using articles on environmental issues'. JCOM 16 (04), A01. https://doi.org/10.22323/2.16040201.

Sachatello-Sawyer, B. and Cohn, T. (2005). 'Native Waters: integrating scientific and cultural ways of knowing about water'. Curator: The Museum Journal 48 (2), pp. 134-140. https://doi.org/10.1111/j.2151-6952.2005.tb00162.x.

Schwartz, B. (2014). 'Communicating science through the performing arts'. Interdisciplinary Science Reviews 39 (3), pp. 275-289. https://doi.org/10.1179/0308018814Z.00000000089.

Stiller-Reeve, M. and Naznin, Z. (2018). 'A climate for art: enhancing scientist-citizen collaboration in Bangladesh'. Bulletin of the American Meteorological Society 99 (3), pp. 491-497. https://doi.org/10.1175/BAMS-D-16-0044.1.

Streicher, B., Unterleitner, K. and Schulze, H. (2014). 'Knowledge ${ }^{\circ}$ rooms - science communication in local, welcoming spaces to foster social inclusion'. JCOM 13 (02), C03. https://doi .org/10.22323/2.13020303.

Varner, J. (2014). 'Scientific outreach: toward effective public engagement with biological science'. BioScience 64 (4), pp. 333-340. https://doi.org/10.1093/biosci/biu021.

von Roten, F. C. and Moeschler, O. (2007). 'Is art a "good" mediator in a Science Festival?' JCOM 06 (03), A02. https://doi .org/10.22323/2.06030202.

Ana Matias is a researcher at the Centre of Marine and Environmental Research, University of Algarve, Portugal. She devoted most of her research to coastal geological processes, and since 2017 her focus has been changing to transdisciplinary research on geoscience, art, and communication. She participated in science \& art communication projects including dance \& coastal geology, electronic music \& ecology, photography \& marine sciences; and neurosciences \& visual art collection. Her current interests also include social inclusion in/through science communication. E-mail: ammatias@ualg.pt.

Andreia Dias is the responsible for the Education Programme for Schools and other Educational Institutions at the Education Department of the Calouste Gulbenkian Museum. Graduated in Fine Arts - Painting from the FBAUL, a PGDip in Teaching of the Visual Arts by the I.E. as well as an academic training in Dance in the Community, has work in the field of artistic education, mediation and research since 2006 and undertook a number of communication actions with different published papers. E-mail: afdias@gulbenkian.pt.

Cláudia Gonçalves. I am passionate about health matters, science, interdisciplinarity as well as interculturality. I am currently doing my Ph.D. in Biology/Neuroscience at Instituto Gulbenkian de Ciência, in Portugal. My background is Psychology and I graduated in Clinical Psychology from Universidade de Lisboa and did part of my Bachelor's degree at Université Bordeaux Ségalen (Bordeaux II, France). I also obtained my Master degree in 
Psychology (Intercultural Psychology) from Université de Moncton, in Canada, and have been working with vulnerable populations.

E-mail: claudiagoncalves144@hotmail.com.

Paulo Nuno Vicente works as an Assistant Professor at Universidade Nova de Lisboa, where he founded in 2016 and since then coordinates iNOVA Media Lab, a R\&D laboratory dedicated to immersive and interactive narrative, human interface technologies, innovation and digital transformation, new media literacies, science communication, social media and information visualization.

E-mail: inovamedialab@fcsh.unl.pt.

Ana Lúcia Mena is the Head of the Public Engagement unit at the Gulbenkian Institute of Science. She is interested in promoting science in society and a closer relation between different science stakeholders. For that purpose, she develops science education programmes, science and art projects, and organizes public events, reaching to different audiences. E-mail: anamena@igc.gulbenkian.pt.

How to cite

Matias, A., Dias, A., Gonçalves, C., Vicente, P. N. and Mena, A. L. (2021). 'Science communication for social inclusion: exploring science \& art approaches'.

JCOM 20 (02), A05. https:/ / doi.org/10.22323/2.20020205. 